\section{REFERENCES}

Lambert, W. E., \& Paivio, A. The influence of noun-adjective order on learning. Canadian Journal of Psychology, 1956, 10 9-12.

Paivio, A. Learning of adjective-noun paired-associates as function of adjective-noun word order and noun abstractness Canadian Journal of Psychology, 1963, 17, 370-379.

Paivio, A. Abstractness, imagery, and meaningfulness in paired-associate learning. Journal of Verbal Learning \& Verbal Behavior, 1965, 4, 32-38.

Paivio, A. Imagery and verbal processes. New York: Holt, Rinehart \& Winston, 1971. P. 518.

Paivio, A., \& Okovita, H. W. Word imagery modalities and associative learning in blind and sighted subjects. Journal of Verbal Learning \& Verbal Behavior, 1971, 10, 506-510.

Thorndike, E. L. Human learning. New York: Appleton-Century-Crofts, 1931 .
Schlaugel, T. F. The dominant method of imagery in blind as compared to sighted adolescents. Journal of Genetic Psychology, 1953, 83, 265-277.

Yarmey, A. D., \& Paivio, A. Further evidence on the effects of word abstractness and meaningfulness in paired-associate learning. Psychonomic Science, 1965, 2, 307-308.

\section{NOTE}

1. Personal communication with J. Kirstein, Director, Rehabilitation Unit, Albany Association of the Blind, Albany, N.Y.

\title{
Wild caught vs inbred mouse strains: Differences in wheel-turn avoidance learning
}

DOMINIC J. ZERBOLIO, Jr.

\author{
University of Missouri, St. Louis, Missouri 63121
}

Three Bar Harbor inbred mouse strains; C57BL/6J, C3H/HeJ, and DBA/2J, and two wild caught but laboratory bred Peromyscus strains; $P$. leucopus and $P$. maniculatus bairdi, were compared over 8 days of acquisition training on a wheel-turn avoidance task. In the acquisition of the conditioned avoidance response, the Bar Harbor inbreds did not differ but were, as a group, significantly better than the wild caught strains. Differences in activity rate were also apparent, but do not account for the differences in avoidance performance. 


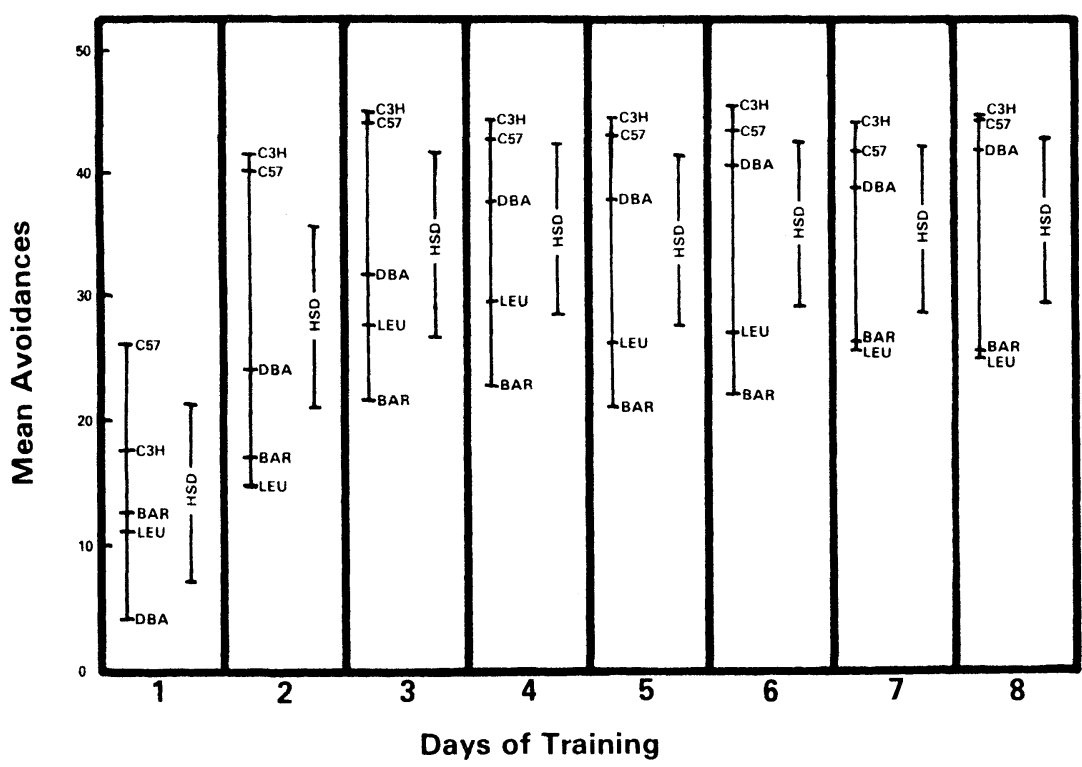

Fig. 1. The mean avoidance performance of the C57BL/6J (C57), DBA/2J (DBA), $\mathrm{C} 3 \mathrm{H} / \mathrm{HeJ}(\mathrm{C} 3 \mathrm{H}), P$. leucopus (LEU), and $P$. maniculatus bairdi (BAR) for 8 days of training. Each day has a 5\% significant difference, interval (HSD) plotted alongside the mean strain performances.
Some authors suggest that domestication produces degenerative animals which are not appropriate for behavioral research (Kavanau, 1964, 1967; Lockard, 1968), but Boice (1973) suggests that domesticated animals may be a logical research model for civilized man. One of the issues is learning capacity. Kavanau (1964) argues that "only" wild animals provide the full range and vigor of responses upon which solutions to central problems of behavior must be based." He also states that Peromyscus (mice) master very complex programs, which may not be even close to the limits of the learning capacity of these wild animals (Kavanau, 1964). Additionally, Kavanau (1967) states "Confined animals (Peromyscus) are likely to seize upon and repeatedly exercise virtually any opportunities to modify their surroundings." In the present study, two Peromyscus strains ( $P$. leucopus and $P$. maniculatus bairdi) are compared with the three Bar Harbor inbreds, C57BL/6J, $\mathrm{DBA} / 2 \mathrm{~J}$, and $\mathrm{C} 3 \mathrm{H} / \mathrm{HeJ}$, on a wheel-turn avoidance task. If Kavanau's assumption about Peromyscus having superior learning capacities has some basis in fact, then a learning task requiring vigorous activity (i.e., wheel-turning) should certainly favor them. This is especially true, since all Bar Harbor strains used are highly selectively inbred for physiological and not behavioral (learning?) characteristics.

\section{METHOD}

\section{Subjects}

Twelve naive 70-80 day old male mice from each of five strains were used. The strains were two wild but laboratory bred strains; $P$. leucopus and $P$. maniculatus bairdi, and three highly inbred Bar Harbor research strains: $\mathrm{C} 3 \mathrm{H} / \mathrm{HeJ}, \mathrm{DBA} / 2 \mathrm{~J}$, and C57BL/6J.
All animals were housed in individual $19 \times 29 \times 14 \mathrm{~cm}$ deep stainless steel pans with ad lib access to food and water throughout the experiment.

\section{Apparatus}

All animals were run in four identical wheel-turn boxes, similar to those described by Zerbolio (1967) with the exception that a stainless steel inside front and rear section was added and connected to the shocker system. All wheel-turn boxes were housed in Scientific Prototype sound proof chambers. The CS was a $1,000-\mathrm{Hz}$ square wave tone at $65-70 \mathrm{~dB}$. The US was $1.0 \mathrm{~mA}$ delivered by separate Grason-Stadler Model E1064GS shocker-scrambler. All programming and recording was accomplished through appropriate au tomatic circuitry.

\section{Procedure}

All animals were run 50 trials a day with a VI-60 (ranging from 20 to $100 \mathrm{sec}$ ) onset-to-onset interval. The CS-US interval was $5 \mathrm{sec}$, with a max imum shock interval of $10 \mathrm{sec}$ if $\mathrm{S}$ failed to respond. A $1 / 4$-turn wheel turn was the minimum response required to terminate either CS or CS and US. Additionally, Ss were observed through viewing ports during sessions, but these data were not quantitatively gathered.

\section{RESULTS}

A 5 strains by 8 days of training repeated measures ANOVA (Winer, 1962) on avoidance performance indicates significant differences between strains $(F=$ 11.40, df $=4 / 55, \mathrm{p}<.01)$ and training effects $(\mathrm{F}=$ 62.27 , df $=7 / 385, \mathrm{p}<.01)$ as well as their interaction $(\mathrm{F}=4.00, \mathrm{df}=28 / 385, \mathrm{p}<.01)$. The mean avoidance performance over the 8 days of training are shown in Fig. 1.

Additional one-way ANOVAs were calculated to generate an error term to allow the calculation of an HSD (honest significant difference) using the Studentized range distribution (Runyon \& Haber, 1971). 
Fig. 2. The mean $\log _{10}$ wheel-turn activity rate of the $\mathrm{C} 57 \mathrm{BL} / 6 \mathrm{~J}$ (C57), DBA/2J (DBA), C3H/HeJ (C3H), $P$. leucopus (LEU) and P. maniculatus bairdi (BAR) for 8 days of training. Each day has a $5 \%$ significant difference interval (HSD) plotted alongside the mean strain performance.

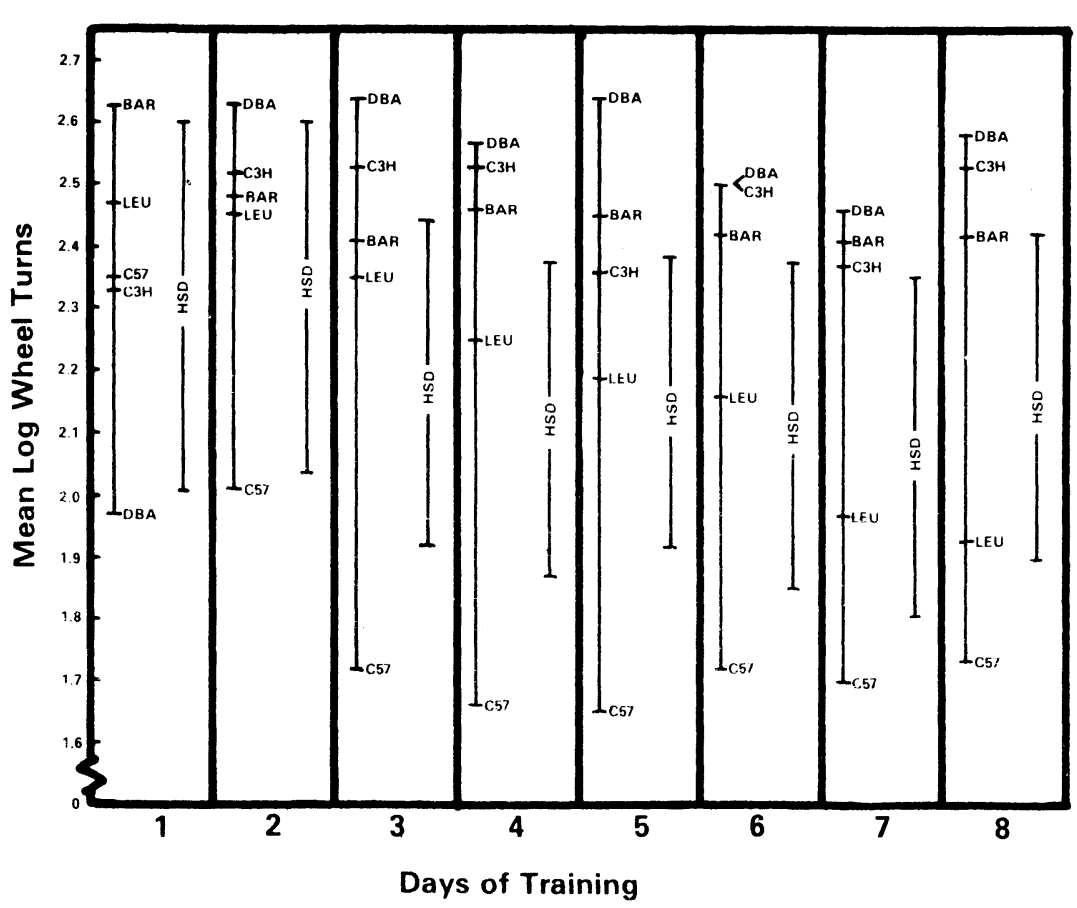

The 5\% difference interval is shown along side each days performance levels in Fig. 1. Any mean avoidance performances differing by this interval or more differ statistically at least at the $5 \%$ level.

A second 5 strains by 8 days of training ANOVA was calculated on the $\log _{10}$ transformed wheel-turn data. The analysis also indicated reliable differences between strains $(\mathrm{F}=8.09, \mathrm{df}=4 / 55, \mathrm{p}<.01)$, days of training $(\mathrm{F}$ $=3.34, \mathrm{df}=7 / 385, \mathrm{p}<.01)$, and their interactions $(\mathrm{F}=$ 4.22, df $=28 / 385, p<.01$ ). The mean $\log _{10}$ transformed wheel-turn data are presented in Fig. 2 for each strain on each day of training. Additional one-way ANOVAs to obtain error terms to calculate HSD intervals were calculated and appear in Fig. 2. Any transformed wheel-turn means differing by this interval or more are statistically different at least at the $5 \%$ level.

\section{DISCUSSION}

The present data clearly show that the three Bar Harbor inbreds are significantly better than the wild-caught strains on the avoidance learning measure (see Fig. 1). Note that by the last days of training, the three inbred strains form a cluster where they do not differ among themselves, but that each inbred strain is significantly better than a second cluster formed by the two Peromyscus strains. These differences in avoidance learning performance do not seem to be predictable from the wheel-turn activity per se, since the $P$. $m$. bairdi are about as active as the DBA and $\mathrm{C} 3 \mathrm{H}$ inbreds, but the $P$. leucopus are similar to the $\mathrm{C} 57$ inbreds. Observations of all animals during running strongly suggests that the avoidance learning differences reflect differences in behavioral plasticity, i.e., the inbreds modify their responses to meet the demands of this situation much more readily than the wild caughts. Boice (1973) has documented this point of view, but advocates of the superiority of wild-caught strains might use alternative argument: that the inbreds are not behaviorally plastic, but behaviorally stereotyped in a manner which is compatible with this task. If the inbreds are assumed to be behaviorally stereotyped, and given that the wild caughts learn significantly less than the inbreds, it is hard to see how one could conclude that the wild caughts are more plastic. It seems that the best interpretation of the wild caughts' performance is that they are also stereotyped, but in a manner which is not task compatible. Either argument, that the inbreds are more plastic than the wild caughts, or that both are nonplastic in different ways does not seem consistent with an argument ending with the conclusion that the wild-caught animals have superior learning capacities.

In sum then, these data do not support Kavanau's (1967) contention of the learning superiority of Peromyscus strains over inbred strains. At best, the selection of inbred or wild-caught strains would be a function of what behaviors the researcher is interested in seeing. The apparent superiority in learning displayed by the inbreds may in fact make inbreds the logical research model for man (Boice, 1973). But to be sure, Barnett's (1967) suggestion that we should not mistake the wile of the wild for cleverness seems, once again, to be justified.

\section{REFERENCES}

Barnett. S. A. Instinct and intelligence. Englewood Cliffs, New Jersey: Prentice-Hall, 1967.

Boice, R. Domestication. Psychological Bulletin, 1973, 80, 215-230.

Kavanau, J. L. Behavior: Confinement, adaptation, and compulsory regimens in laboratory studies. Science, 1964, $143,490$.

Kavanau, J. L. Behavior of captive white-footed mice. Science, $1967,155,1623-1639$.

Lockard, $R$. B. The albino rat: A defensible choice or a bad habit? American Psychologist, 1968, 23, 734-742.

Runyon, R. P., \& Haber, A. Fundamentals of behavioral statistics. (2nd ed.) Reading, Massachusetts: Addison-Wesley, 1971.

Winer, B. J. Statistical principles in experimental design. New York: McGraw-Hill, 1962.

Zerbolio, D. J., Jr. Differences between three inbred mouse strains on a wheel-turn avoidance task. Psychonomic Science, 1967, 7, 201-202.

(Received for publication April 12, 1974.) 